\title{
Assessment of malaria transmission changes in Africa, due to the climate impact of land use change using Coupled Model Intercomparison Project Phase 5 earth system models
}

\author{
Adrian M. Tompkins, Luca Caporaso \\ Abdus Salam International Centre for Theoretical Physics, Trieste Italy
}

\begin{abstract}
Using mathematical modelling tools, we assessed the potential for land use change (LUC) associated with the Intergovernmental Panel on Climate Change low- and high-end emission scenarios (RCP2.6 and RCP8.5) to impact malaria transmission in Africa. To drive a spatially explicit, dynamical malaria model, data from the four available earth system models (ESMs) that contributed to the LUC experiment of the Fifth Climate Model Intercomparison Project are used. Despite the limited size of the ESM ensemble, stark differences in the assessment of how LUC can impact climate are revealed. In three out of four ESMs,
\end{abstract}

Correspondence: Adrian M. Tompkins, Abdus Salam International Centre for Theoretical Physics, Strada Costiera 11, 34152 Trieste, Italy.

Tel: +39.040 .2240111 - Fax: +39.040 .224163 .

E-mail: tompkins@ictp.it

Key words: Land use change; Malaria; Climate change; Environment; Health.

Acknowledgements: This research was supported by the European Commission Seventh Framework Research Programme under HEALTHY FUTURES (266327) and the authors thank colleagues from the project, in particular Andy Morse and David Taylor, for their feedback on this work. Two anonymous reviewers gave very detailed and helpful feedback on the first submitted version of this manuscript. The ESM data used in this study was obtained directly from the respective modelling centres and Bill Merryfield, Vivek Arora (CANESM), Shingo Watanabe (MIROC), Nathalie de Noblet (IPSL), and Victor Brovkin (MPI) are thanked for their help in this matter. Since this research was conducted, all the ESM data has been made available on the CMIP5 public repositories. All VECTRI model output will be archived at ICTP for a period of 5 years and is available on request.

Contributions: the authors contributed equally.

Conflict of interest: the authors declare no potential conflict of interest.

Received for publication: 25 May 2015.

Accepted for publication: 3 March 2016.

(C) Copyright A.M. Tompkins and L. Caporaso, 2016

Licensee PAGEPress, Italy

Geospatial Health 2016; 11(s1):380

doi:10.4081/gh.2016.380

This article is distributed under the terms of the Creative Commons Attribution Noncommercial License (CC BY-NC 4.0) which permits any noncommercial use, distribution, and reproduction in any medium, provided the original author(s) and source are credited. the impact of LUC on precipitation and temperature over the next century is limited, resulting in no significant change in malaria transmission. However, in one ESM, LUC leads to increases in precipitation under scenario RCP2.6, and increases in temperature in areas of land use conversion to farmland under both scenarios. The result is a more intense transmission and longer transmission seasons in the southeast of the continent, most notably in Mozambique and southern Tanzania. In contrast, warming associated with LUC in the Sahel region reduces risk in this model, as temperatures are already above the $25-30^{\circ} \mathrm{C}$ threshold at which transmission peaks. The differences between the ESMs emphasise the uncertainty in such assessments. It is also recalled that the modelling framework is unable to adequately represent local-scale changes in climate due to LUC, which some field studies indicate could be significant.

\section{Introduction}

Future changes to the size of human population, and its energy and agricultural systems, could lead to considerable changes in the way land is used and the resulting land cover. Such changes could have significant implications for the transmission of infectious diseases (Foley et al., 2005), particularly those involving an intermediate vector such as malaria (Patz and Olson, 2006).

Land use change (LUC) may affect malaria transmission through a wide range of pathways; many of which are poorly studied and understood, and are summarised in Figure 1. Firstly, LUC impacts the physical environment, in particular the flow of water over the surface and its retention in ponds and pools. Mosquitoes rely on the availability of water for oviposition, with the key malaria vectors Anopheles gambiae and arabiensis preferring temporary sunlit pools and puddles, so that in areas lacking permanent water bodies, transmission is closely tied to the rainy season with a lag of one to two months (Bomblies et al., 2009). The availability and suitability of breeding sites is highly heterogeneous and, in addition to climate, depends on topography, soil texture and land cover type (Norris, 2004). Forest conversion to agriculture will likely produce more poorly drained soils, especially in the initial years after land conversion (Packard, 2007) and reduced vegetation, while canopy cover reductions increase the availability of sun lit ponds. The type of land use will also be relevant. For instance, irrigated crops may further increase breeding sites, although the resultant increased income may reduce overall population vulnerability and reduce overall malaria prevalence (ljumba and Lindsay, 2008).

Studies on the availability of breeding sites in different land cover environments are limited, but fieldwork conducted in the highlands of Kenya found that breeding sites on farmland or pasture were more frequently occupied with larvae than those found in forests (Minakawa et al., 2005; Munga et al., 2009; Mutuku et al., 2009). This could be the 
result of differences in vegetative shading, with Tuno et al. (2005) showing gambiae larvae survival being an order of magnitude greater in sunlit ponds in cleared areas relative to shady pools in forests. However, they could also be due to the second aspect of LUC (Figure 1), namely the changing in vector-host dynamic, where the density of anthropophilic vectors increases in response to the increasing host in population density associated with land development (possibly at the expense of alternative mosquito species).

The complexity of the relationship between hydrology, land use and vectors was emphasised in the reviews of Walsh et al. (1993) and Yasuoka and Levins (2007), who highlighted that deforestation could both increase or decrease malaria incidence depending on the local situation. To date, these effects have rarely been considered in any dynamical modelling assessment of potential future risk in response to LUC, due to the lack of quantitative data that allow their encapsulation in simple mathematical relationships. Vanwambeke et al. (2007) attempted to model breeding site availability and resulting larvae density in an empirical model for Thailand, but such model is yet to be coupled to dynamical models of malaria transmission.

The third mechanism by which LUC may impact malaria is by altering climate (Figure 1). Malaria is highly climate-sensitive (Martens et al., 1995a, 1995b). In addition to the provision of breeding sites by rainfall, intense rainfall can flush breeding sites of earlier stage larvae (Paaijmans et al., 2007), leading to a nonlinear relationship between rain and malaria cases (Thomson et al., 2006; Lowe et al., 2013). Wind affects host location by the vector and vector dispersion (Lindsay et al., 1995; Cardé and Willis, 2008), while relative humidity impacts vector survival (Mayne, 1930; Lyons et al., 2014). Air temperature is key as it impacts the sporogonic and gonotrophic cycle length and also impacts the vector mortality rate. The temperature of the water in which the vector larvae develop, which is related to air temperature, also affects their development rate and mortality (Bayoh and Lindsay, 2003; Bayoh and Lindsay, 2004; Kirby and Lindsay, 2009). The combined effect is that malaria increases with air temperature until transmission peaks at $25-30^{\circ} \mathrm{C}$, thereafter decreasing (Lunde et al. 2013a; Mordecai et al., 2013).

Many numerical (often idealised) earth system model studies of LUC, mostly focusing on its manifestation as deforestation for the creation of agricultural land or pasture, have documented significant potential impacts on climate (Lean and Warrilow, 1989; Shukla et al., 1990; Nobre et al., 1991; Henderson-Sellers et al., 1993; Polcher and Laval, 1994; McGuffie et al., 1995; Zhang et al., 1996; Taylor et al., 2002; Nogherotto et al., 2013). For example, forest conversion to agricultural land use alters the surface roughness, the albedo and the evapotranspiration. Conducted over sufficient spatial area, these changes can impact rainfall and temperature both locally, and also remotely through teleconnections. However, the modelling work has often been contradictory. Even the sign of the precipitation changes is uncertain, for example, with deforestation leading to increases or decreases, depending on the Earth System Model (ESM) in question. Bell et al. (2015) recently attempted to dissect these findings, dividing the impact of LUC into its constituent changes to albedo, surface roughness and evapotranspiration. The latter two effects dominated, but the work showed that the climatic reaction to LUC was complex and included feedbacks with the large-scale, dynamics. Moreover, ESMs still run at spatial scales that can only account for regional scale changes in land cover,

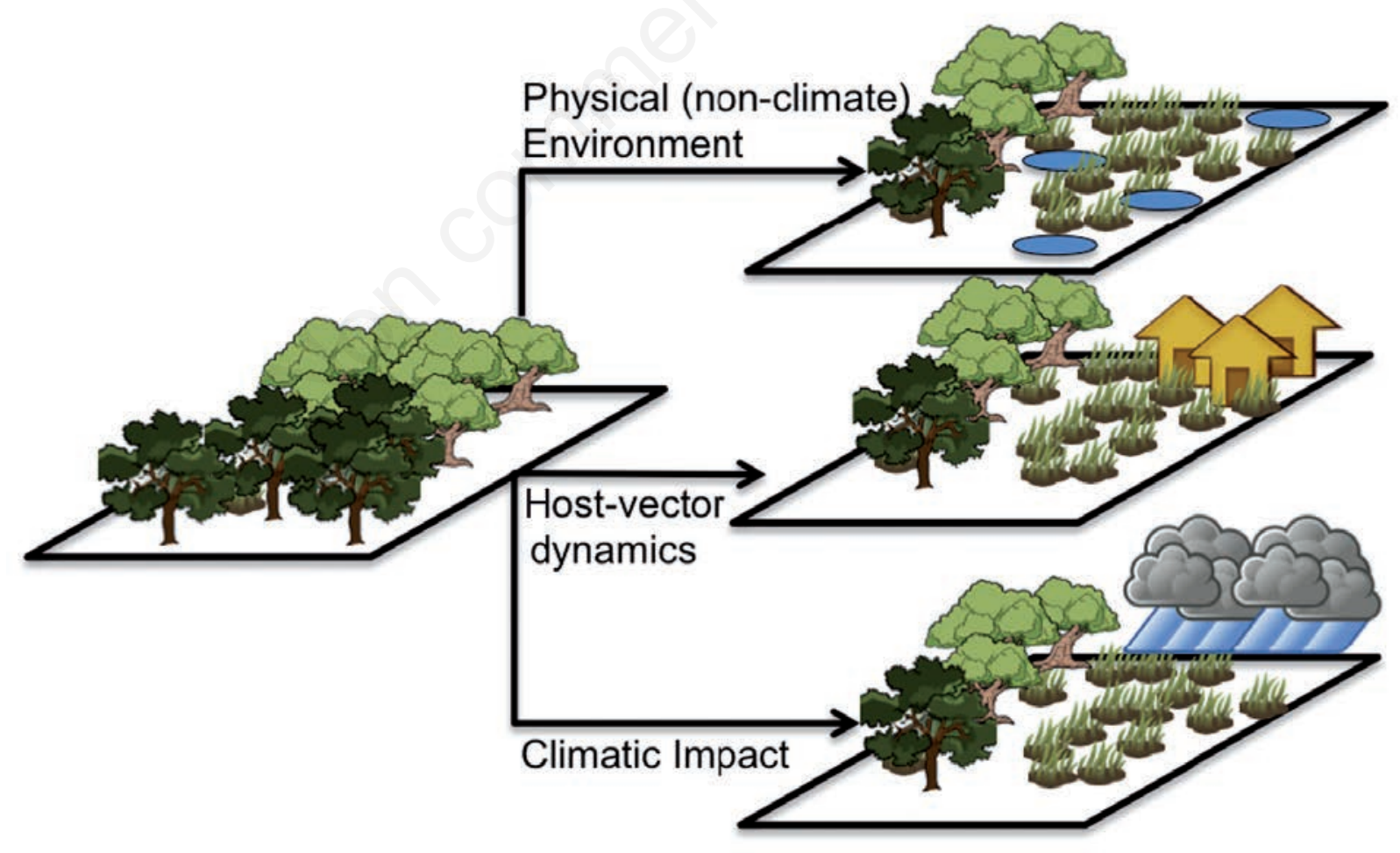

Figure 1. Schematic of potential pathways for land use change (LUC) to impact malaria transmission. LUC affects the physical environment, for example by changing the soil drainage characteristics and the thus the availability of breeding sites (top). The proportion of sun-lit pools could alter as a result of reductions in canopy cover. Vector-host dynamics could alter through changes in the predominate vector species or closer proximity of human habitations to breeding sites (middle). LUC has also been shown to alter temperature, rainfall and relative humidity, which would also impact malaria transmission (lower). 
and are unable to resolve the local impact of land cover changes that are smaller in scale, such as the introduction of rice culture. We will return to the theme of spatial scale in the discussion.

The climate impact of LUC could thus be potentially significant for malaria transmission. In fact, Lindblade et al. (2000) and Afrane et al. $(2005,2006)$ identified this climate mechanism as the key influence of LUC on malaria transmission in their local study in the highlands of Kenya, and it was also highlighted in the reviews of Patz et al. (2005) and Patz and Olson (2006). Modelling studies on the impact of LUC on malaria have been limited. To our best knowledge, the only direct modelling study incorporating LUC was the one by Ermert et al. (2012) using the Liverpool malaria model (Hoshen and Morse, 2004; Ermert et al., 2011). This was driven by climate information generated by a regional ESM that included future potential LUC in addition to changes in anthropogenic greenhouse gases. They quoted a strong impact of LUC on malaria in this study, although no separate experiments were conducted to isolate the influence of the LUC. Moreover, due to the use of a single ESM, no assessment of climate model uncertainty can be derived (Ermert et al., 2012).

Many of the cited global and regional climate modelling studies that investigated the climate impact of LUC used idealised experimental frameworks, instigating complete and instantaneous deforestation of entire basins such as the Congo (Nogherotto et al., 2013; Bell et al. 2015). Such changes far exceed the anticipated LUC over the next century. Recently, the Coupled Model Intercomparison Project Phase 5 (CMIP5), that contributed to the Intergovernmental Panel on Climate Change (IPCC) $5^{\text {th }}$ assessment report, included an optional experimental line that attempted to include more realistic representation of LUC. Twin experiments with and without LUC projections resulted in limited climate impacts in most models, with the results highly model-dependent (Pitman et al., 2009; Brovkin et al., 2013). It should be noted that Brovkin et al. (2013) masks out 30 year mean differences if they are not statistically greater than the respective model's year to year variability; a strict test that assumes interannual variability is equal to decadal variability. As a result, most changes are deemed insignificant, except over oceanic areas of known strong decadal variability.

In this article the research of Ermert et al. (2012) will be taken further by the use of twin experiments with and without LUC in order to isolate its impact, conducted by the suite of ESMs that participated in the CMIP5 process using the LUC scenarios consistent with the emission scenario storyline of the IPCC. The use of an ensemble of four different climate models rather than the single modelling system in Ermert et al. (2012) permits a preliminary assessment of the uncertainty related to the way LUC is incorporated into ESMs and the interaction between atmosphere and the land surface. These climate integrations will be used to drive a spatially explicit dynamical malaria model to produce the first multi-model assessment of the potential impact of LUC on malaria transmission in Africa via its impact on climate.

\section{Materials and Methods}

\section{Land use change in earth system models}

The latest generation of representative concentration pathways (RCPs) are associated with a story-line for future anthropogenic LUC that was converted to a common gridded format for use in climate modelling studies (Van Vuuren et al., 2011b). One optional experimental line of the latest round of the climate model intercomparison project (CMIP5) involved the twin investigation of future climate with and without LUC represented. Each of the impact assessment models (IAMs) that produced a RCP included scenarios that involved LUC decisions. However, the land use classifications and their spatial resolutions (distributed, national level) mean that for the use in ESM integrations, a harmonisation process was required. This was achieved using the History of the Global Environment model (HYDE v3.1), resulting in an internally consistent database combining historical population, cropland and pasture statistics with satellite information and allocation algorithms to generate spatial land-cover maps (Goldewijk et al., 2010; Klein Goldewijk et al., 2011), which then smoothly connected historical land-use data with future projections in a format more readily accessible to ESMs (Hurtt et al., 2011). The resulting datasets provide yearly fractional land-use data for the time period (1500-2100) at 0.5 degrees of horizontal resolution. These land use maps were then incorporated into five global models, each of which implemented various rules to translate the HYDE land class and their conversions to the plant functional type (PFT) definitions of various land surface schemes used in the ESMs. This additionally involved devising rules to deal with internal inconsistencies for the two models in which the dynamical vegetation model was active. Of the five ESMs which participated in the LUC experiment of CMIP5, complete daily data were made available from four models within the timeframe of this study, and thus the HADGEM-ES2 model is not considered further. A summary of the methodologies employed to implement the LUC projections into these four ESMs is given in Table 1. The models differ concerning the implementation of dynamical vegetation modelling and the number and classification of PFTs in the respective land surface schemes. Thus, although the ESMs use the same harmonized land-use scenarios, the method employed to convert HYDE categories into land categories and PFTs used by ESMs differs between the models, as does the translation of HYDE trends to PFT conversion pathways. For example, crop increases in CANESM2 result in a reduction in the fractional coverage of herbaceous and woody PFTs, proportional to their existing coverage,

Table 1. Summary of the key land surface details relevant for the History Database of the Global Environment 3.1 conversion.

\begin{tabular}{|c|c|c|c|c|}
\hline ESM & CanESM2 & IPSL-CM5A-LR & MIROC-ESM & MPI-ESM-LR \\
\hline Land model & CTEM & ORCHIDEE & SEIB-DGVM & JSBACH \\
\hline Reference & Arora and Boer (2010) & Krinner et al. (2005) & Sato et al. (2007) & Raddatz et al. (2007) \\
\hline PFTs classes & 9 & 13 & 13 & 12 \\
\hline DVM & No & No & Yes & Yes \\
\hline HYDE output & Absolute values & Absolute values & Transition matrix & Transition matrix \\
\hline
\end{tabular}

HYDE conversion Woody + herbaceous $=$ natural $\quad$ Woody + herbaceous $=$ natural $\quad$ Primary + secondary $=$ natural $\quad$ Primary + secondary $=$ natural ESM, Earth System Model; CanESM2, Canadian Earth System Model version 2; IPSL-CM5A-LR, Institute Pierre Simon Laplace version 5a; MIROC-ESM, Model for Interdisciplinary Research on Climate; MPI-ESM-LR, Max Planck Institute Earth System Model; CTEM, Canadian Terrestrial Ecosystem Model; ORCHIDEE (Organising Carbon and Hydrology In Dynamic Ecosystems; SEIB-DGVM, spatially explicit individual-based Dynamic Global Vegetation Model; JSBACH, (Jena Scheme for Biosphere-Atmosphere Coupling in Hamburg; PFT, plant functional type; DVM, Dynamic Vegetation Model; HYDE, History Database of the Global Environment. 
while the IPSL-CM5A-LR model reduces all natural vegetation types. Reductions in crop area are compensated for by increases in all natural coverage types in both models, while MIROC-ESM explicitly simulates forest regrowth after pasture abandonment. In the MPI-ESM-LR model pasture area increases at the expense of forest if the pasture exceeds the availability of the grasses and shrubs category, similar, but not identical to MIROC-ESM, which converts grassland prior to forest, while CANESM2 does not alter pasture. Such differences regard the intricate detail of the respective model coding and are not always explicitly documented in the literature. To isolate the impact of LUC on climate, the participating CMIP5 groups performed two sets of simulations for the period 2006-2100 using the same forcing as for RCP2.6 and RCP8.5 but with the land-use invariant through the time (Brovkin et al., 2013). The RCP8.5 scenario predicts a rising of the radiative forcing pathway leading to $8.5 \mathrm{Wm}^{-2}$ top-of-atmosphere forcing by 2100 , while the RCP2.6 scenario expects a peak in radiative forcing at approximately $3 \mathrm{Wm}^{-2}$, declining to $2.6 \mathrm{Wm}^{-2}$ by 2100 .

The two scenarios for land use for RCP2.6 and RCP8.5 are derived respectively from IMAGE IAM (Van Vuuren et al., 2011a) and MESSAGE IAM (Riahi et al., 2011). The socioeconomic scenarios associated with both of the RCPs predict an increase of cropland area (Figure 2), but while in RCP8.5 this is due to the increase of human population and associated food and fuel requirements, in RCP2.6 the change is a result of the desire to move towards greater bio-energy production to reduce $\mathrm{CO}_{2}$ emissions. In fact, the increase in crop land at the expense of primary land cover is actually greatest in RCP2.6. In contrast, the pasture area is assumed to remain almost constant in RCP2.6, while an increase occurs in RCP8.5 (Van Vuuren et al., 2011b).

\section{Malaria model}

The malaria model used in this study is the VECTRI model (Tompkins and Ermert, 2013), a gridded mathematical model for malaria transmission that accounts for temperature in the larvae and adult life cycles, while rainfall drives a model for surface pond coverage that has been improved and evaluated (Asare et al., 2016a; 2016b). The model has been applied to seasonal forecasting tasks (Tompkins and Di Giuseppe, 2015) and has been evaluated using sentinel site and district case data from Uganda and Rwanda (Tompkins et al., 2016a), as well as applied to climate change problems (Caminade et al., 2014). The model accounts for human population density, which in these studies is frozen at present day values given by the Worldpop dataset (Tatem et al., 2007; Linard et al., 2012). Thus future population growth, urbanisation or changes in cyclic migration (Tatem and Smith, 2010;
Wesolowski et al., 2012; Tompkins and McCreesh, 2016) do not impact the projections reported here. This study uses version v1.3.3 of the VECTRI model, which additionally represents larvae growth rates using the relationship of Craig et al. (1999), and water-temperature dependent larvae mortality rates derived from a combination of the growth rate and the data of Bayoh and Lindsay (2003) and Bayoh and Lindsay (2004). The temperature experienced by the adult mosquito is assumed to be an average of the outdoor air temperature (measured at the standard 2 metre station height) and the derived indoor hut temperature. The latter is derived from the 2 metre air temperature using the relationship given in Lunde et al. (2013b). This modification improves the model performance at colder temperature ranges below $21^{\circ} \mathrm{C}$ since it prevents endophilic vectors being subjected to cold night time temperatures.

The malaria transmission changes are assessed using two metrics in this study. The first is the malaria parasite prevalence, which is referred to as the parasite ratio (PR) and is commonly used as a broad measure for malaria transmission intensity (Omumbo et al., 2005). The second metric is the length of the transmission season (LTS), which is calculated as the number of days where the daily entomological inoculation rate (EIR, the number of infectious bites received per person per unit time) exceeds 0.01 as used in Caminade et al. (2014).

\section{Experimental set up}

Daily precipitation and temperature output from the four available ESMs was used to drive the VECTRI model for the model's historical run (1960-2005) and the two RCPs (2005-2099). The simulations are conducted and then analysed for the whole of Africa, with an additional focus on the East African Community region of the HEALTHY FUTURES project. As temperature is key for simulating malaria in the correct geographical locations, we applied a simple bias correction in which the mean annual cycle of temperature bias with respect to the 1960-2005 Climatic Research Data mean (CRU; Harris et al., 2014) is subtracted from each integration. Rainfall is used without correction. The numerical expense limited the number of earth system model integrations that were conducted for the land use experiment: three ensemble members for Canadian Earth System Model version 2 (CanESM2), two ensemble members for the Max Planck Institute Earth System Model (MPI-ESM-LR) and just a single integration of the Institute Pierre Simon Laplace version 5a (IPSL-CM5A-LR) and the Model for Interdisciplinary Research on Climate (MIROC-ESM) models. No statistical significance testing is conducted, as it is not possible for the two models only running a single integration and the statistical power

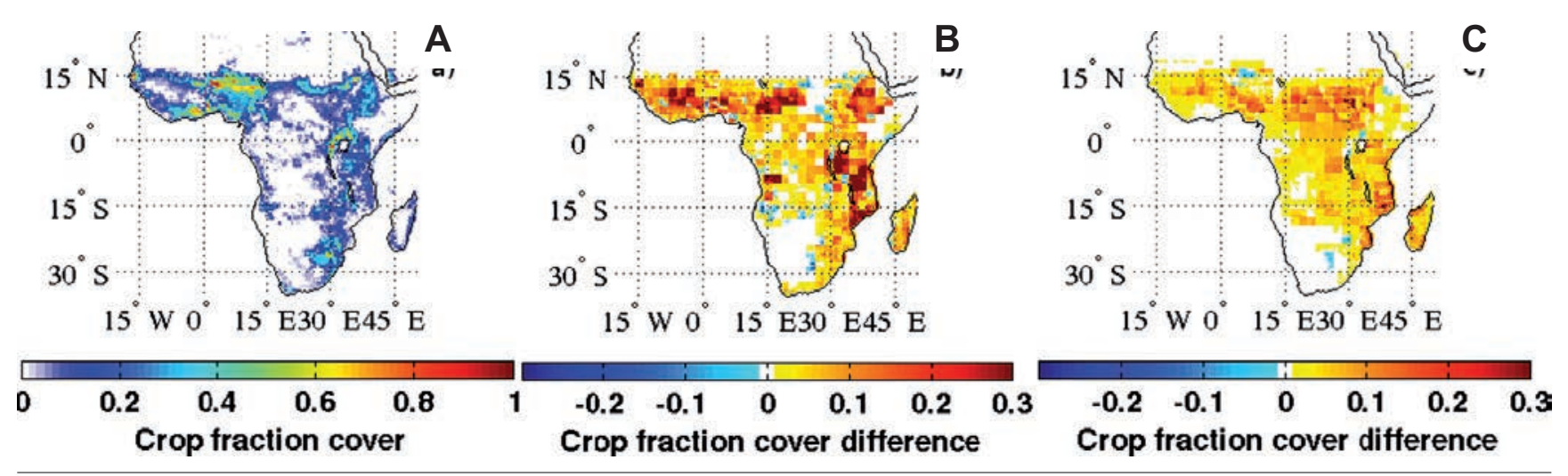

Figure 2. A) Present day crop fraction in Africa and the changes projected to occur by 2099 under (B) RCP2.6 and (C) RCP8.5. 
will be low for the models with the sample sizes of 2 and 3 . In an attempt to minimize the effect of small ensemble sizes, differences are investigated for a long averaging period of 70 years (2030 to 2099).

\section{Results}

\section{Impact of land use change on climate}

The impact of LUC on climate is assessed in terms of two variables only, the 2 metre air temperature and precipitation, as these are the two climate-related inputs to the malaria model. Understanding the impact of LUC on climate is complex, since it involves feedbacks with the large-scale dynamics, and is also a function of how the land use conversions are translated into each model's PFT categories and the relative physiological properties assigned to the class. Without the possibility to conduct further sensitivity experiments with each ESM it is impossible, and thus beyond the scope of the present work, to discern why each ESM responds to LUC in a particular way.

The precipitation difference between the experiments with and without LUC for the period 2030 to 2099 for emissions scenario RCP2.6 (Figure 3) show small magnitude changes that are for the most part less than $0.3 \mathrm{~mm} \mathrm{day}^{-1}$, considerably less than the changes observed due to greenhouse gas emissions (IPCC, 2014). Again, this emphasises the stark need for more than one ensemble member in such experiments to allow robust significance testing to be conducted, and also to be able to correctly attribute the relative contribution of model configuration and natural variability to uncertainty. Looking closely at individual models, the response is very limited in the IPSL-CM5A-LR and CanESM2 models. The MPI-ESM-LR model also has a small response, which is manifested in a small increase in precipitation throughout much of sub-Saharan Africa. From the 4 models, MIROC-ESM exhibits the strongest response to LUC, with local changes up to $1 \mathrm{~mm}$ day $^{-1}$. The magnitude of precipitation changes due to LUC in the RCP8.5 sce-

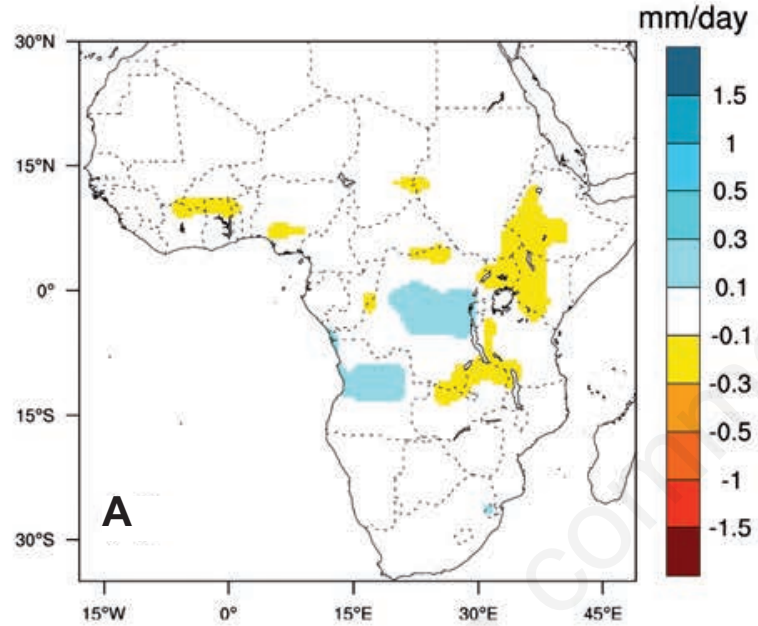

$\mathrm{mm} /$ day
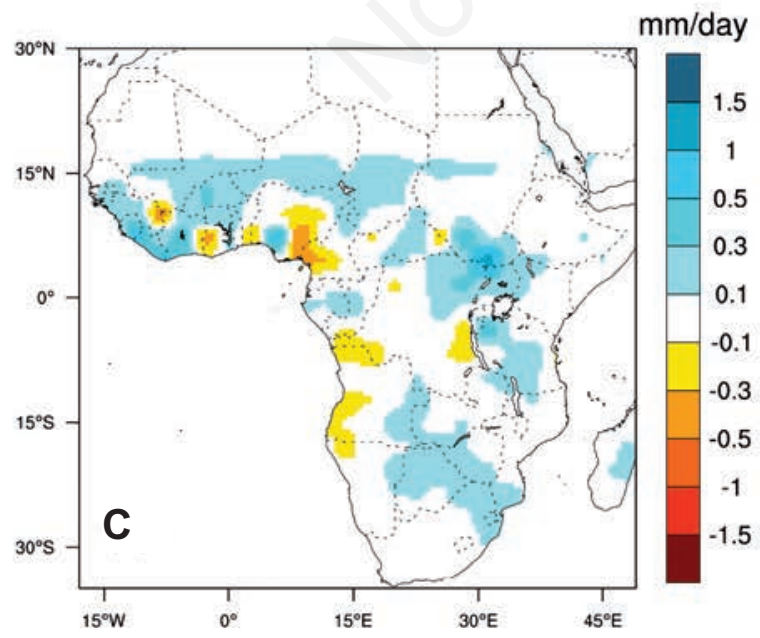

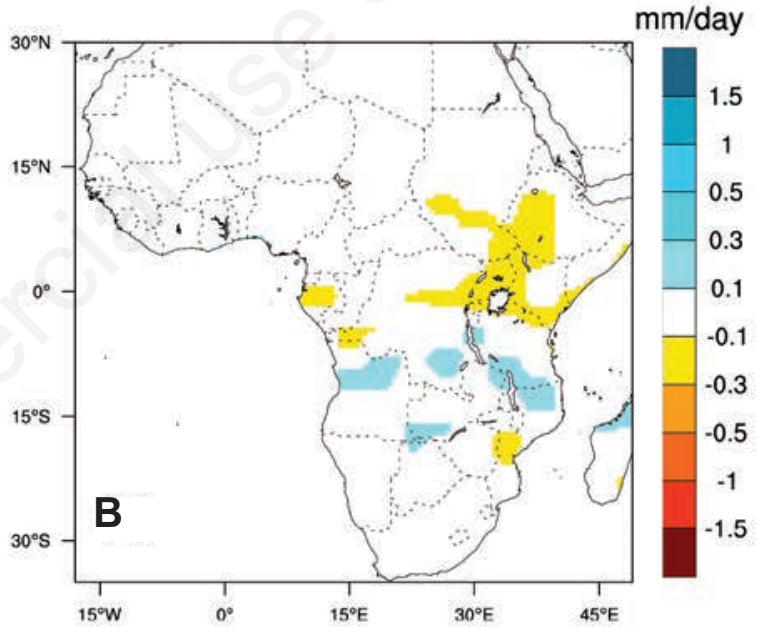

$\mathrm{mm} /$ day

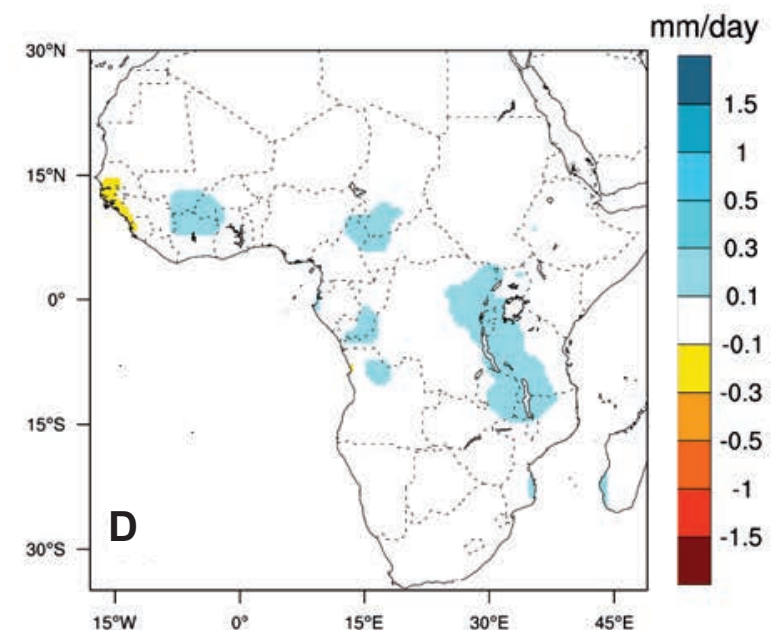

Figure 3. Precipitation differences averaged for the period 2030-2099 due to the land use change scenario associated with RCP2.6 simulated with Earth System Model (A) Canadian Earth System Model version 2, B) Institute Pierre Simon Laplace version 5a, C) Model for Interdisciplinary Research on Climate, and D) Max Planck Institute Earth System Model. 
nario are even smaller than RCP2.6, due to the smaller rate of land conversion (Figure 2) and are not shown here for brevity. However, we note that the patterns of changes are distinct between the scenarios, reflecting the contrasting patterns of LUC.

The temperature changes are also very limited in three of the models, with MIROC-ESM again showing the strongest impact of LUC, which in places exceeds $1^{\circ} \mathrm{C}$ in RCP2.6 (Figure 4). In the MIROC-ESM model, the south-eastern area of Africa shows strong warming, along with areas of West Africa, which coincide with the location of maximum conversion to agricultural land (Figure 2) and is a result of changes to evapotranspiration efficiency and albedo.

\section{Impact of land use change on malaria transmission}

As the impact of LUC on climate is minor in the CanESM2, IPSLCM5A-LR and MPI-ESM-LR ESMs relative to the order of magnitude larger changes that result from greenhouse gas emissions, even in the RCP2.6 scenario (IPCC, 2014), a limited impact on malaria in those models is expected. Using the LTS metric this is indeed seen to be the case (Figure 5). In the IPSL-CM5A-LR, MPI-ESM-LR and CanESM2 models, LTS changes are mostly less than 10 days. Only the MIROCESM model produces substantial changes, with the transmission season increasing by up to two months per year in south-eastern Africa, over the northern part of Mozambique and Tanzania. Over the Sahel region, decreases in the length of the transmission season occur. If the temperature is referred to Figure 5, it is seen that there is a direct correspondence between regions of changing temperature and malaria impact, but that the sign of the correlation changes. Above about 25$30^{\circ} \mathrm{C}$, malaria transmission decreases with increasing mean temperature (Craig et al., 1999) and warming in the already warm Sahel region (warmer still in the 2030-2099 period due to greenhouse gas emission) thus reduces LTS.

Focusing attention on the East Africa Community (EAC) region as simulated by the MIROC-ESM model, the model with the greatest response to LUC; Figure 6 shows the climate impact of both RCP2.6 and
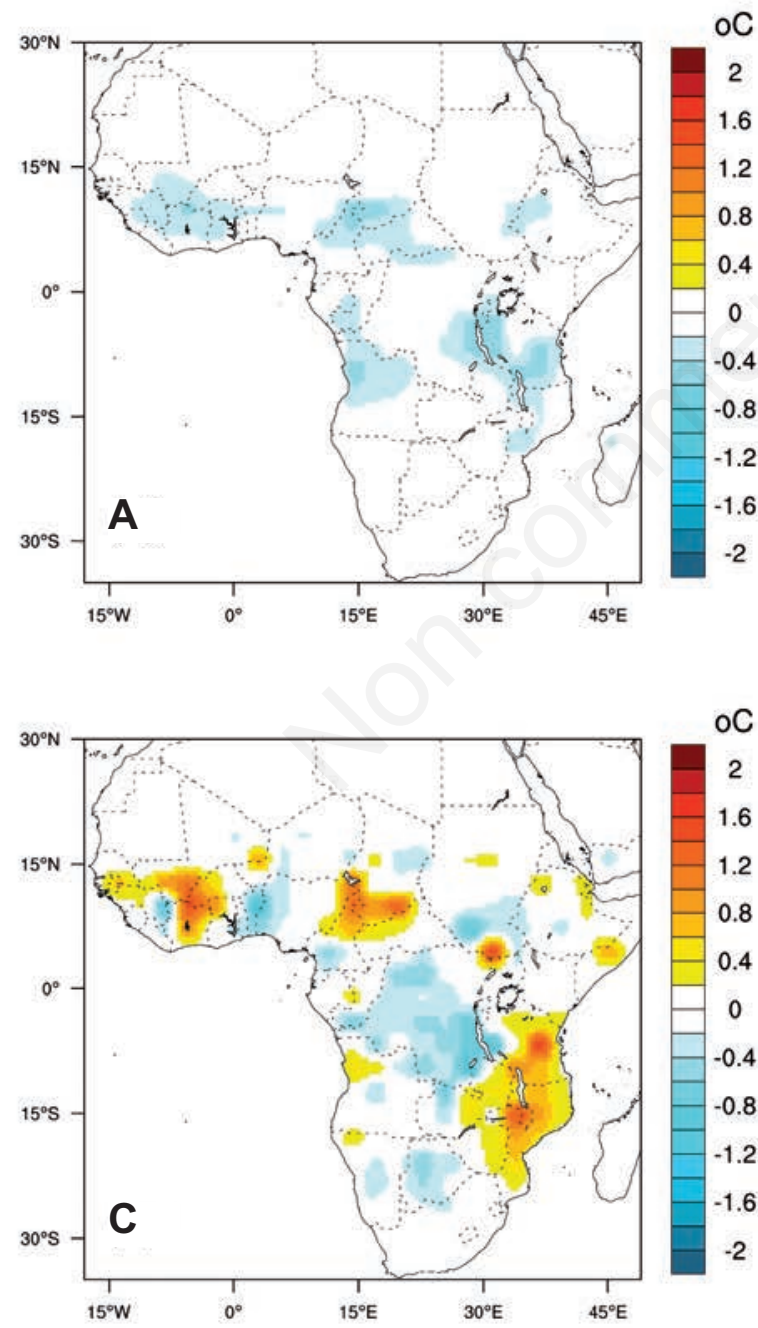
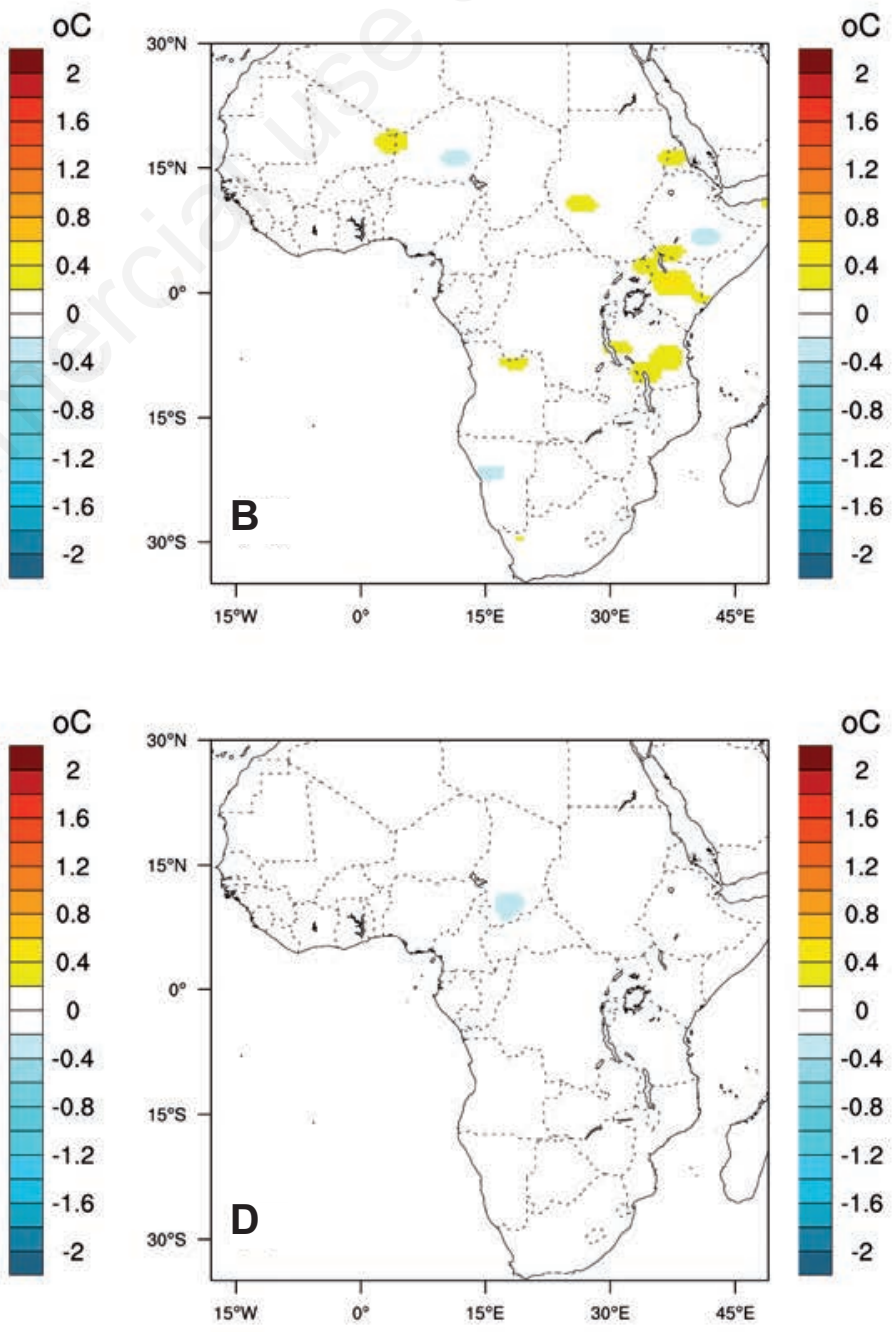

Figure 4. Temperature differences averaged for the period 2030-2099 due to the land use change scenario associated with RCP2.6 simulated with Earth System Model (A) Canadian Earth System Model version 2, B) Institute Pierre Simon Laplace version 5a, C) Model for Interdisciplinary Research on Climate, and D) Max Planck Institute Earth System Model. 


\section{Discussion}

to an increase in temperature over south-eastern Tanzania and over the north of Uganda, accompanied by small increases in precipitation. The second region of high LUC to the south-west of lake Victoria is not reflected in a change in temperature, but does seem to be associated with a precipitation change. The climate signal due to the LUC in RCP8.5 bears some similarity to RCP2.6, particularly with regard to temperature changes (Figure 7B,D).

The changes in PR and LTS due to LUC in the two RCPs for the MIROC-ESM model (Figure 7) highlight the strong correspondence between temperature changes and malaria. The PR and LTS increase throughout most of Tanzania in response to the climate warming caused by LUC in this model, while cooling over the higher ground of Burundi and Rwanda leads to reduced malaria. It is notable that the limited rainfall changes have little impact. One exception is the north of Uganda, where both temperature and rainfall increases coincide. The result is a small increase in prevalence $(<5 \%)$.
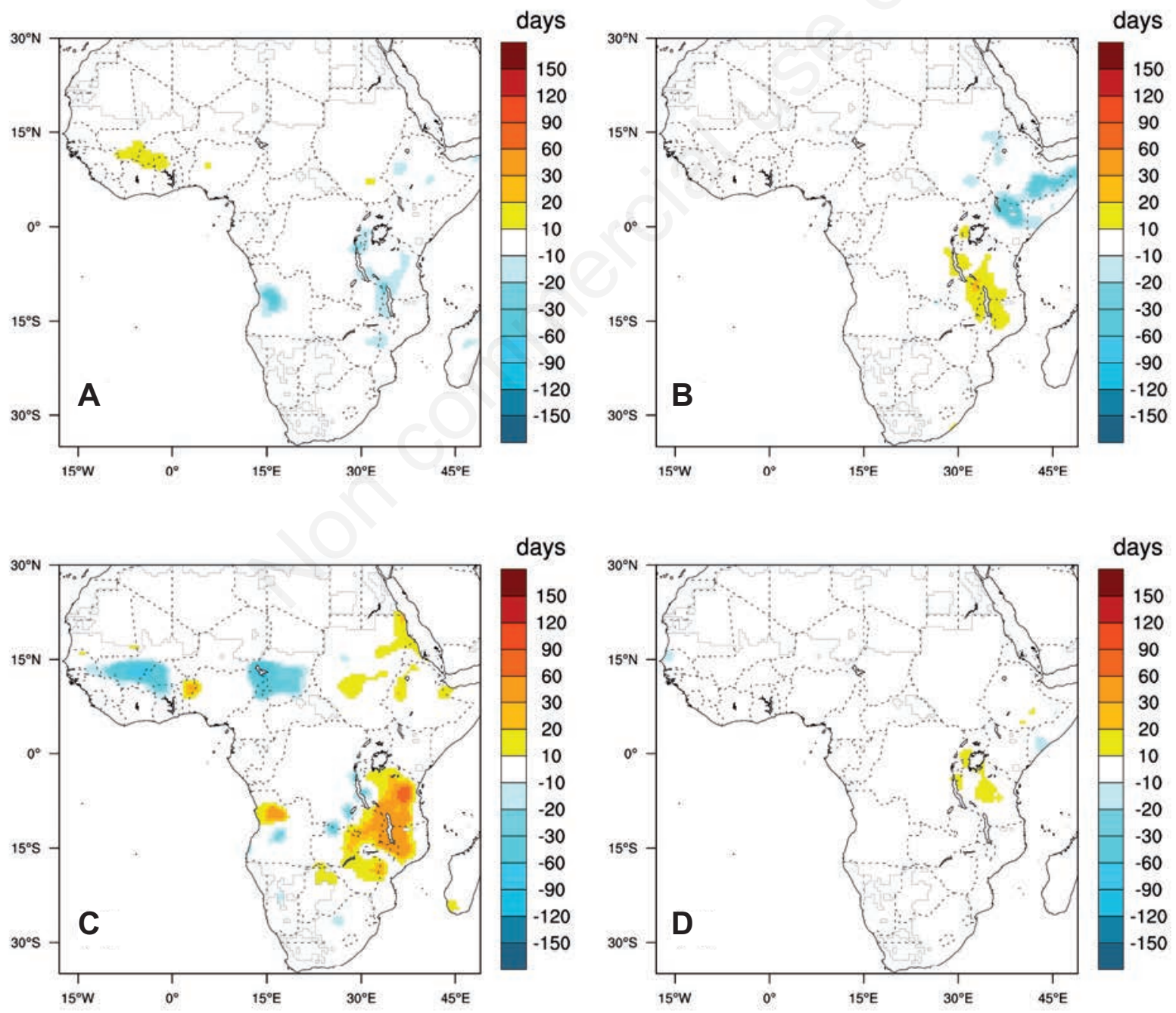

Figure 5. Length of transmission season differences averaged for the period 2030-2099 due to the land use change scenario associated with RCP2.6 simulated with Earth System Model (A) Canadian Earth System Model version 2, B) Institute Pierre Simon Laplace version 5a, C) Model for Interdisciplinary Research on Climate, and D) Max Planck Institute Earth System Model. 
parameter ensembles for single location runs. Thus the limited ensemble size of initial conditions and modelling systems implies that the results of this study should be taken as merely indicative of potential impacts. In three of the four available ESMs, LUC has a very limited impact on climate, contrasting with the MIROC-ESM ESM, which showed a more significant impact. Thus in three of the models the changes in simulated malaria transmission as a result of LUC climate change were very minor, while the MIROC-ESM model shows increases in precipitation and temperature under scenario RCP2.6 and associated increases in malaria transmission and resulting prevalence in the southeast of the continent, including Tanzania in the focus EAC region.
In contrast, reductions were seen over the Sahel region due to temperature increases occurring in already warm locations exceeding $30^{\circ} \mathrm{C}$.

The MIROC-ESM model has a very spatially heterogeneous response in comparison with the other models. This indicates that certain land cover conversion pathways (e.g. forest conversion to agriculture) demanded by the LUC scenario have been focused in isolated grid cells in the MIROC-ESM's model implementation of the HYDE land use (LU) maps. This high heterogeneity in the LUC pathway allocation method would likely increase the local magnitude of the change. In contrast, the other models tend to show a more uniform climate response, possibly indicating a more spatially homogeneous LUC.
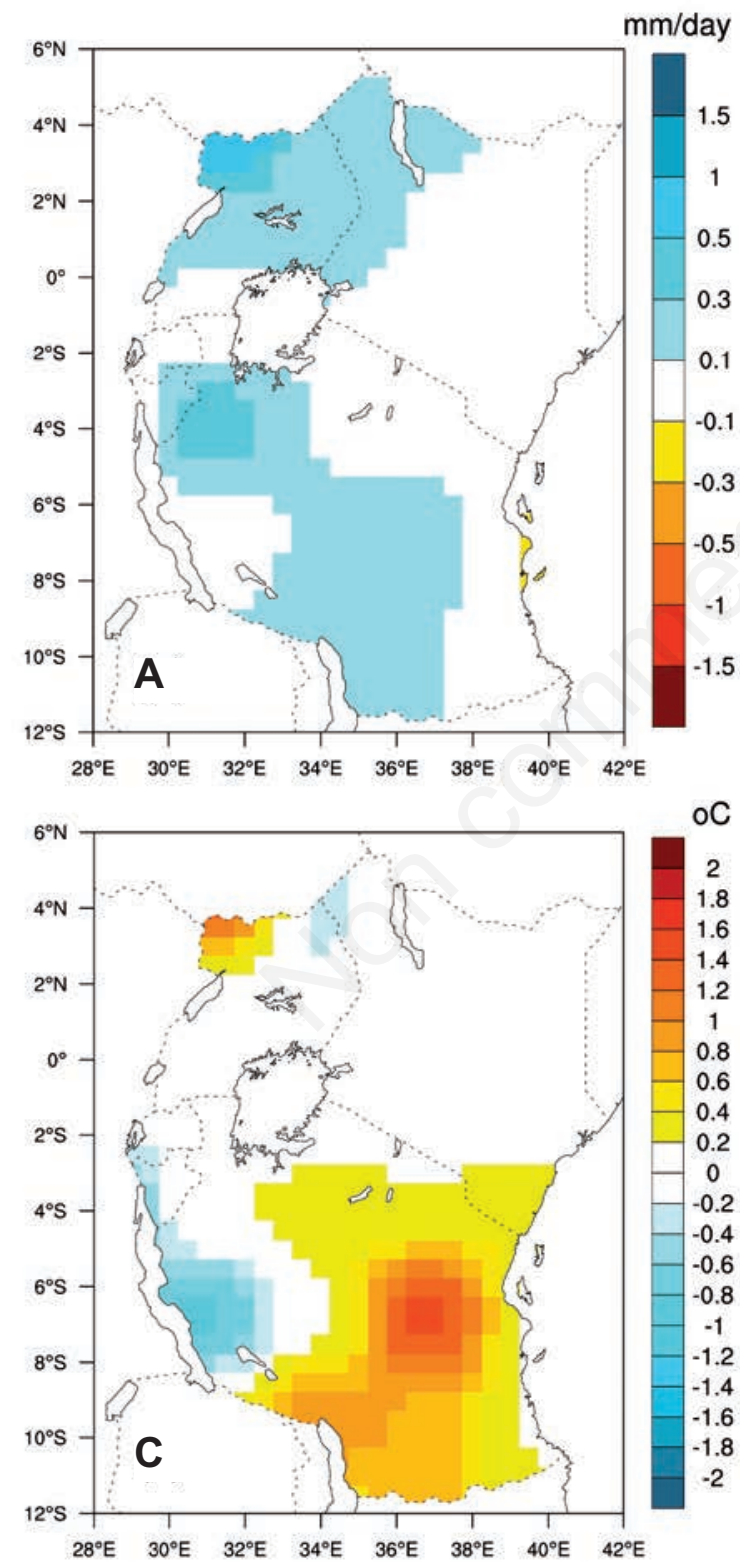
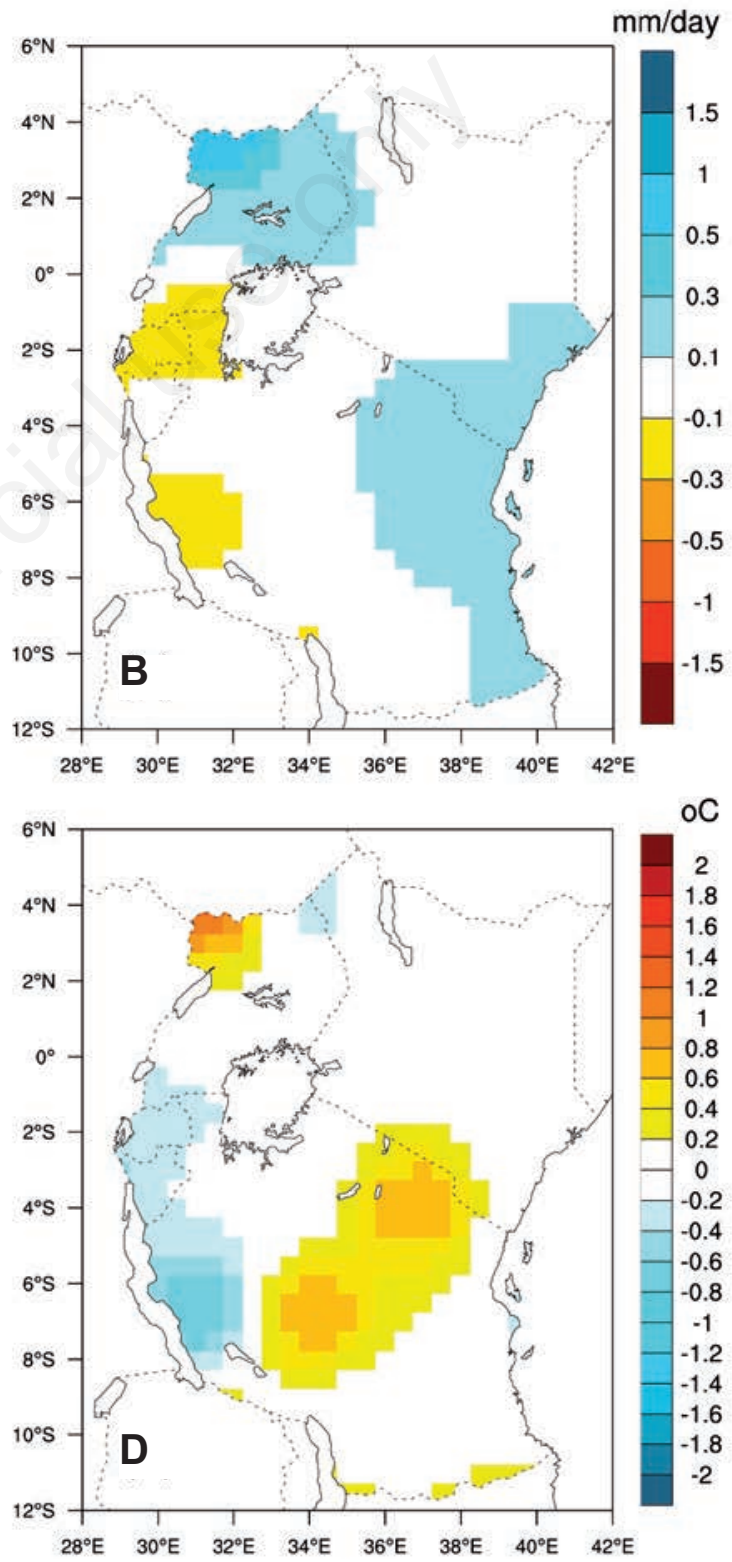

Figure 6. The HEALTHY FUTURES EAC region of changes in rainfall (A, B) and temperature (C, D) averaged for the period 20302099 due to the land use change scenario simulated with the Model for Interdisciplinary Research on Climate for emissions scenarios (A, C) RCP2.6 (B, D) RCP8.5. 
The fact that LUC leads to very limited climate changes in three of the ESMs that contributed to the LUCID experiment emphasizes that many of the previous studies overstate the potential changes during the next century with their idealized boundary conditions that implement complete land conversion in a region. However, the wide range of responses between the four models also highlights the considerable uncertainty in projecting the climate impacts of LUC in the current generation of ESMs.

Another concern is the fact that the methodology for implementing LUC in the ESMs differs from model to model, confounding the attempt to translate underlying patterns of LUC to the climate change signal observed. The starkly different responses between the ESMs to the same driving LUC scenario is not only a result of the differing atmos- pheric model processes such as deep convection, but is likely to be connected with the way the LUC is mapped to the land cover classes of the land surface scheme used in each ESM, and the relative properties of those classes. The MIROC-ESM model was identified as having a particularly heterogeneous implementation of the LUC pathways, for example. Certain LUCs pathways, such as the introduction of irrigation, are not represented at all. Often such changes occur on scales that are not adequately represented, even with the tile land surface schemes. It is also recalled that the study only examines one pathway from LUC to malaria transmission, namely via changes in climate. Taking irrigation as an example, while it certainly impacts local climate (Lobell et al., 2009), it also provides more breeding opportunities and may result in closer contact between human and the vector (Carnevale
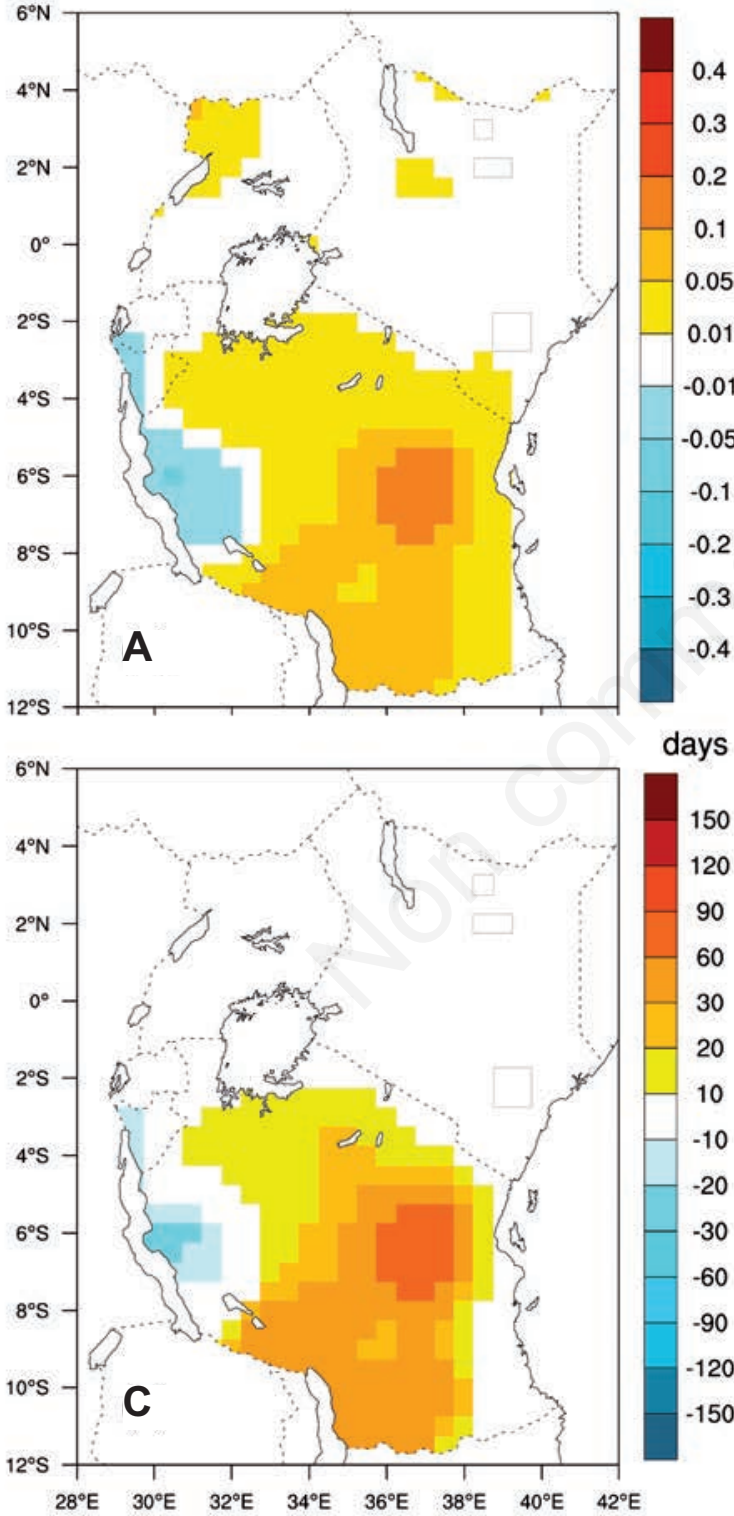

days

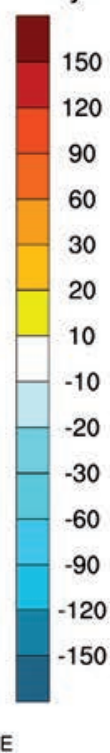

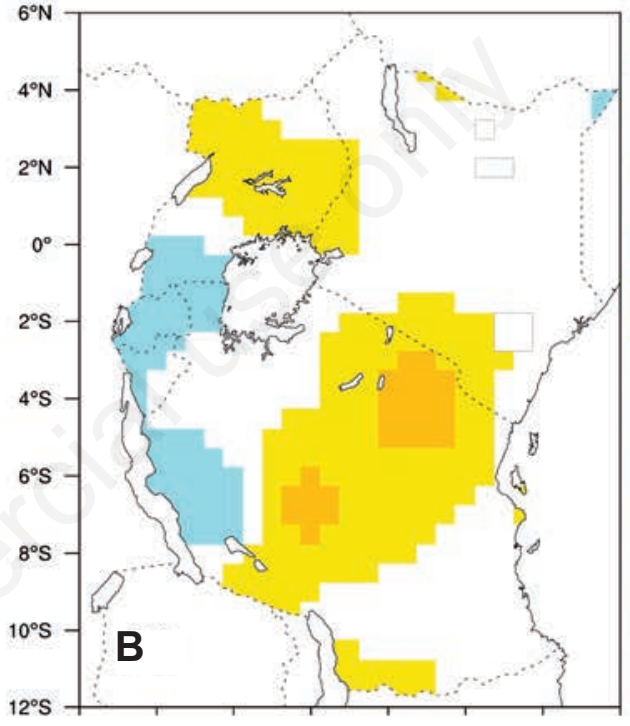

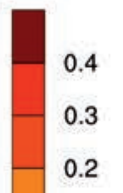

0.1

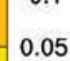

0.01

$-0.01$

$-0.05$

$-0.1$

$-0.2$

$-0.3$

$-0.4$

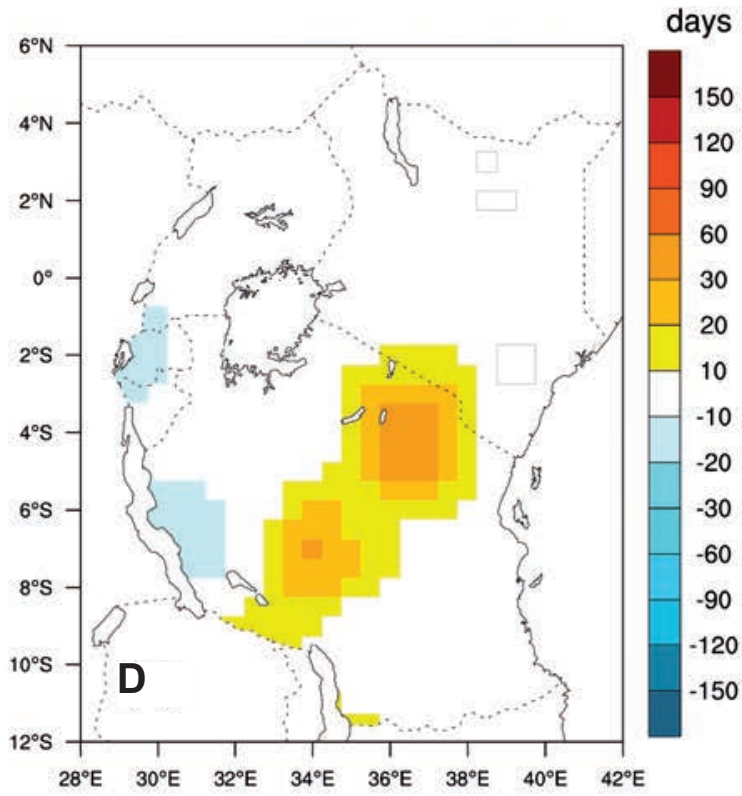

Figure 7. Zoom over the HEALTHY FUTURES EAC region of changes in parasite ratio (PR) and length of transmission season (LTS) averaged for the period 2030-2099 due to the land use change scenario simulated with the Model for Interdisciplinary Research on Climate for (A) PR, RCP2.6 (B) PR, RCP8.5 (C) LTS, RCP2.6 (D) LTS, RCP8.5. 
and Robert, 1987; Mukiama and Mwangi, 1989; Keiser et al., 2004). In contrast, the review of Ijumba and Lindsay (2008) showed that irrigation could reduce overall risk due the associated socioeconomic development.

The issue of scale is an important one, and should be emphasized. Since the fact that this study has tended to find a relatively limited impact of LUC on malaria via climate does not contradict or conflict necessarily with the field observations of Lindblade et al. (2000) and Munga et al. (2009), which indicate that the local changes may be significant. Moreover, sub-national scale developments may be missing from the LUC assessments. Using the HYDE scenarios, it appears here that Kenya is relatively unaffected by LUC, but it should be recalled that the projections for land use are large-scale in nature and do not account for individual national level development plans. For example, as part of its vision 2030 plan, Kenya plans to develop the north east of the country in the so-called Lamu Port and South Sudan Ethiopia Transport (LAPSSET) Corridor project (Johannes et al., 2015). This project entails large-scale infrastructure development, in addition to water management schemes and agriculture farming (both plantations and cattle) initiatives. Apart from the direct impact of such schemes on land use and land cover, such a plan is likely to increase internal population movements substantially, with significant numbers of people projected to move to the development region, further enhancing LUC. Such national-scale development projects are not included in present impact assessment models, which generally rely on coarse estimates of future development potential.

\section{Conclusions}

This work has used state-of-the-art climate model simulations to drive a dynamical malaria model and demonstrated that LUC has the potential to impact malaria transmission in Africa, but that the effect appears minor relative to previous studies of potential climate change impact (Caminade et al., 2014). In the focus EAC region, LUC leads to increases in the length of the transmission season of one to two months in Tanzania in one of the four available climate models. The study highlighted the wide range of climate responses to the underlying LUC scenarios, emphasizing the uncertainty in the way LUC is currently incorporated into ESMs. Sub-national and local scale LUC impacts are likely to be significant but are not represented in the present modelling framework. Improving the assessment of the LUC effect by addressing the above short-comings of the present work would therefore involve defining a common framework for interfacing LUC scenarios with the land schemes of ESMs, possibly using local downscaling deforestation and LUC tools such as the FOREST-SAGE model presented in Tompkins et al. (2015). Increasing the ESM ensemble, both by using a wider range of models as well as increasing the ensemble size with each model, and employing an ensemble of malaria models would allow uncertainties in the modelling hierarchy to be evaluated. Finally, fine scale local and regional studies should be conducted to complement the global integrations. In addition, assessing the impact of LUC on the availability of breeding sites is a challenge that needs to be addressed in order to allow other pathways between LUC and disease exposure to be represented. In order to do this, a much improved understanding of the small-scale hydrology of the disease is required to supplement the geographically isolated studies that already exist.

\section{References}

Afrane YA,. Lawson BW, Githeko AK, Yan G, 2005. Effects of microclimatic changes caused by land use and land cover on duration of gonotrophic cycles of Anopheles gambiae (Diptera: Culicidae) in western Kenya highlands. J Med Entomol 42:974-80.

Afrane YA, Zhou G, Lawson BW, Githeko AK, Yan G, 2006. Effects of microclimatic changes caused by deforestation on the survivorship and reproductive fitness of Anopheles gambiae in western Kenya highlands. Am J Trop Med Hyg 74:772-8.

Arora V, Boer G, 2010. Uncertainties in the 20th century carbon budget associated with land use change. Glob Bhange Biol 16:3327-48.

Asare E0, Tompkins AM, Amekudzi LK, Ermert V, 2016a. A breeding site model for regional, dynamical malaria simulations evaluated using in situ temporary ponds observations. Geospat Health 11:390.

Asare EO, Tompkins AM, Bomblies A, 2016b. Evaluation of a simple puddle breeding site model for malaria vectors using high resolution explicit surface hydrology simulations. PLoS One [In press].

Bayoh MN, Lindsay SW, 2003. Effect of temperature on the development of the aquatic stages of Anopheles gambiae sensu stricto (Diptera: Culicidae). Bull Entomol Res 93:375-81.

Bayoh MN, Lindsay SW, 2004. Temperature-related duration of aquatic stages of the Afrotropical malaria vector mosquito Anopheles gambiae in the laboratory. Med Vet Entomol 18:174-9.

Bell JP, Tompkins AM, Bouka-Biona C, Sanda IS, 2015. A process-based investigation into the impact of the Congo basin deforestation on surface climate. J Geophys Res 120:5721-39.

Bomblies A, Duchemin JB, Eltahir EAB, 2009. A mechanistic approach for accurate simulation of village scale malaria transmission. Malaria J 8:223.

Brovkin V, Boysen L, Arora VK, Boisier JP, Cadule P, Chini L, Claussen M, Friedlingstein P, Gayler V, van den Hurk BJJM, Hurtt GC, Jones CD, Kato E, de Noblet-Ducoudré N, Pacifico F, Pongratz J, Weiss M, 2013. Effect of anthropogenic land-use and land-cover changes on climate and land carbon storage in CMIP5 projections for the twenty-first century. J Climate 26:6859-81.

Caminade C, Kovats S, Rocklov J, Tompkins AM, Morse AP, ColónGonzález FJ, Stenlund H, Martens P, Lloyd SJ, 2014, Impact of climate change on global malaria distribution. P Natl Acad Sci USA 111:3286-91.

Cardé RT, Willis MA, 2008. Navigational strategies used by insects to find distant, wind-borne sources of odor. JCE 34:854-66.

Carnevale P, Robert V, 1987. Introduction of irrigation in Burkina Faso and its effect on malaria transmission. Effects of agricultural development on vector-borne diseases. FAO Ed., Rome, Italy

Craig MH, Snow RW, le Sueur D, 1999. A climate-based distribution model of malaria transmission in sub-Saharan Africa. Parasitol Today 15:105-11.

Ermert V, Fink AH, Jones AE, Morse AP, 2011. Development of a new version of the Liverpool malaria model. I. Refining the parameter settings and mathematical formulation of basic processes based on a literature review. Malaria J 10:35.

Ermert V, Fink AH, Morse AP, Paeth H, 2012. The impact of regional climate change on malaria risk due to greenhouse forcing and landuse changes in tropical Africa. Environ Health Perspect 120:77-84.

Foley JA, Defries R, Asner GP, Barford C, Bonan G, Carpenter SR, Chapin FS, Coe MT, Daily GC, Gibbs HK, Helkowski JH, Holloway T, Howard EA, Kucharik CJ, Monfreda C, Patz JA, Prentice IC, Ramankutty N, Snyder PK, 2005. Global consequences of land use. 
Science 309:570-4.

Goldewijk KK, Beusen A, Janssen P, 2010. Long-term dynamic modeling of global population and built-up area in a spatially explicit way: Hyde 3.1. Holocene 20:565-73.

Harris I, Jones PD, Osborn TJ, Lister DH, 2014. Updated high-resolution grids of monthly climatic observations-the CRU TS3. 10 Dataset. Int J Climatol 34:623-42.

Henderson-Sellers A, Dickinson RE, Durbidge TB, Kennedy PJ, McGuffie K, Pitman AJ, 1993. Tropical deforestation: modeling local to regional-scale climate change. J Geophys Res 98:7289-15.

Hoshen MB, Morse AP, 2004. A weather-driven model of malaria transmission. Malaria J 3:32.

Hurtt GC, Chini LP, Frolking S, Betts RA, Feddema J, Fischer G, Fisk JP, Hibbard K, Houghton RA, Janetos A, Jones CD, Kindermann G, Kinoshita T, Goldewijk KK, Riahi K, Shevliakova E, Smith S, Stehfest E, Thomson A, Thornton P, van Vuuren DP, Wang YP, 2011. Harmonization of land-use scenarios for the period 1500-2100: 600 years of global gridded annual land-use transitions, wood harvest, and resulting secondary lands. Climat Change 109:117-61.

Ijumba JN, Lindsay SW, 2008. Impact of irrigation on malaria in Africa: paddies paradox. Med Vet Entomol 15:1-11.

IPCC, 2014. Climate change 2014: synthesis report. Contribution of Working Groups I, II and III to the fifth assessment report of the Intergovernmental Panel on Climate Change. IPCC, Geneva, Switzerland. $151 \mathrm{pp}$.

Johannes EM, Zulu LC, Kalipeni E, 2015. Oil discovery in Turkana County, Kenya: a source of conflict or development? Afr Geograph Rev 34:142-64.

Kay J, Deser C, Phillips A, Mai A, Hannay C, Strand G, Arblaster JM, Bates SC, Danabasoglu G, Edwards J, Holland M, Kushner P, Lamarque JF, Lawrence D, Lindsay K, Middleton A, Munoz E, Neale R, Oleson K, Polvani L, Vertenstein M, 2015. The community earth system model (CESM) large ensemble project: a community resource for studying climate change in the presence of internal climate variability. Bull Am Meteor Soc 96:1333-49.

Keiser J, Utzinger J, De Castro MC, Smith TA, Tanner M, Singer BH, 2004. Urbanization in sub-saharan Africa and implication for malaria control. Am J Trop Med Hyg 71:118-27.

Kirby MJ, Lindsay SW, 2009. Effect of temperature and inter-specific competition on the development and survival of Anopheles gambiae sensu stricto and An. arabiensis larvae. Acta Trop 109:118-23.

Klein Goldewijk K, Beusen A, Van Drecht G, De Vos M, 2011. The hyde 3.1 spatially explicit database of human-induced global land-use change over the past 12,000 years. Global Ecol Biogeogr 20:73-86.

Krinner G, Viovy N, de Noblet-Ducoudré N, Ogée J, Polcher J, Friedlingstein P, Ciais P, Sitch S, Prentice IC, 2005. A dynamic global vegetation model for studies of the coupled atmosphere-biosphere system. Global Biogeochem Cycles 19:GB1015.

Lean J, Warrilow DA, 1989. Simulation of the regional climatic impact of Amazon deforestation. Nature 342:411-3.

Linard C, Gilbert M, Snow RW, Noor AM, Tatem AJ, 2012. Population distribution, settlement patterns and accessibility across Africa in 2010. PLoS One 7:e31 743.

Lindblade KA, Walker ED, Onapa AW, Katungu J, Wilson ML, 2000. Land use change alters malaria transmission parameters by modifying temperature in a highland area of Uganda. Trop Med Int Health 5:263-74.

Lindsay S, Schellenberg JA, Zeiler H, Daly R, Salum F, Wilkins H, 1995. Exposure of Gambian children to Anopheles gambiae malaria vectors in an irrigated rice production area. Med Vet Entomol 9:50-8.

Lobell D, Bala G, Mirin A, Phillips T, Maxwell R, Rotman D, 2009.
Regional differences in the influence of irrigation on climate. $\mathrm{J}$ Climate 22:2248-55.

Lowe R, Chirombo J, Tompkins AM, 2013. Relative importance of climatic, geographic and socio-economic determinants of malaria in Malawi. Malaria J 12:416.

Lunde TM, Bayoh MN, Lindtjørn B, 2013a. How malaria models relate temperature to malaria transmission. Parasite Vector 6:1-10.

Lunde TM, Korecha D, Loha E, Sorteberg A, Lindtjørn B, 2013b. A dynamic model of some malaria-transmitting anopheline mosquitoes of the Afrotropical region. I. Model description and sensitivity analysis. Malar J 12:28.

Lyons CL, Coetzee M, Terblanche JS, Chown SL, 2014. Desiccation tolerance as a function of age, sex, humidity and temperature in adults of the African malaria vectors Anopheles arabiensis Patton and Anopheles funestus Giles. J Exp Biol 217:3823-33.

Martens WJM, Jetten TH, Rottmans J, Niessen LW, 1995a. Climate change and vector-borne diseases: a global modelling perspective. Glob Environ Change 5:195-209.

Martens WJM, Niessen LW, Rotmans J, Jetten TH, McMichael AJ, 1995b. Potential impact of global climate change on malaria risk. Environ Health Perspect 103:458-64.

Mayne B, 1930. A study of the influence of relative humidity on the life and infectibility of the mosquito. IJMR 17:1119-37.

McGuffie K, Henderson-Sellers A, Zhang H, Durbidge TB, Pitman AJ, 1995. Global climate sensitivity to tropical deforestation. Global Planet Change 10:97-128.

Meehl GA, Moss R, Taylor KE, Eyring V, Stouffer RJ, Bony S, Stevens B, 2014. Climate model intercomparisons: preparing for the next phase. EOS Trans Am Geophys U 95:77-8.

Minakawa N, Munga S, Atieli F, Mushinzimana E, Zhou G, Githeko AK, Yan G, 2005. Spatial distribution of anopheline larval habitats in Western Kenyan highlands: effects of land cover types and topography. Am J Trop Med Hyg 73:157-65.

Mordecai EA, Paaijmans KP, Johnson LR, Balzer C, Ben-Horin T, de Moor E, McNally A, Pawar S, Ryan SJ, Smith TC, Lafferty KD, 2013. Optimal temperature for malaria transmission is dramatically lower than previously predicted. Ecol Lett 16:22-30.

Mukiama TK, Mwangi RW, 1989. Seasonal population changes and malaria transmission potential of Anopheles pharoensis and the minor anophelines in Mwea irrigation scheme, Kenya. Acta Trop 46:181-9.

Munga S, Yakob L, Mushinzimana E, Zhou G, Ouna T, Minakawa N, Githeko A, Yan G, 2009. Land use and land cover changes and spatiotemporal dynamics of anopheline larval habitats during a fouryear period in a highland community of Africa. Am J Trop Med Hyg 81:1079-84.

Mutuku FM, Bayoh MN, Hightower AW, Vulule JM, Gimnig JE, Mueke JM, Amimo FA, Walker ED, 2009. A supervised land cover classification of a western Kenya lowland endemic for human malaria: associations of land cover with larval Anopheles habitats. Int $\mathbf{J}$ Health Geographics 8:19.

Nobre C, Sellers P, Shukla J, 1991. Amazonian deforestation and regional climate change. J Climate 4:957-88.

Nogherotto R, Coppola E, Giorgi F, Mariotti L, 2013. Impact of Congo basin deforestation on the African monsoon. Atmos Sci Lett 14:45-51.

Norris DE, 2004. Mosquito-borne diseases as a consequence of land use change. Eco Health 1:19-24.

Omumbo JA, Hay SI, Snow RW, Tatem AJ, Rogers DJ, 2005. Modelling malaria risk in East Africa at high-spatial resolution. Trop Med Int Health 10:557-66.

Paaijmans KP, Wandago MO, Githeko AK, Takken W, 2007. Unexpected 
high losses of Anopheles gambiae larvae due to rainfall. PLoS One 2:e1146.

Packard RM, 2007. The making of a tropical disease: a short history of malaria. Johns Hopkins University Press, 296 pp.

Patz JA, Campbell-Lendrum D, Holloway T, Foley JA, 2005. Impact of regional climate change on human health. Nature 438:310-7.

Patz JA, Olson SH, 2006. Malaria risk and temperature: influences from global climate change and local land use practices. P Natl Acad Sci USA 103:5635-6.

Piontek F, Müller C, Pugh TA, Clark DB, Deryng D, Elliott J, Colón González Fde J, Flörke M, Folberth C, Franssen W, Frieler K, Friend AD, Gosling SN, Hemming D, Khabarov N, Kim H, Lomas MR, Masaki Y, Mengel M, Morse A, Neumann K, Nishina K, Ostberg S, Pavlick R, Ruane AC, Schewe J, Schmid E, Stacke T, Tang Q, Tessler ZD, Tompkins AM, Warszawski L, Wisser D, Schellnhuber HJ, 2014. Multisectoral climate impact hotspots in a warming world. P Natl Acad Sci USA 111:3233-8.

Pitman A, de Noblet-Ducoudre N, Cruz FT, Davin EL, Bonan GB, Brovkin V, Claussen M, Delire C, Ganzeveld L, Gayler V, van den Hurk BJJM, Lawrence PJ, MK van der Molen, Muller C, Reick CH, Seneviratne SI, Strengers BJ, Voldoire A, 2009. Uncertainties in climate responses to past land cover change: first results from the LUCID intercomparison study. Geophys Res Lett 36:L14814.

Polcher J, Laval K, 1994. The impact of African and Amazonian deforestation on tropical climate. J Hydrol 155:389-405.

Raddatz T, Reick CH, Knorr W, Kattge J, Roeckner E, Schnur R, Schnitzler KG, Wetzel P, Jungclaus J, 2007. Will the tropical land biosphere dominate the climate-carbon cycle feedback during the twenty-first century? Clim Dyn 29:565-74.

Riahi K, Rao S, Krey V, Cho C, Chirkov V, Fischer G, Kindermann G, Nakicenovic N, Rafaj P, 2011. RCP 8.5 - A scenario of comparatively high greenhouse gas emissions. Climatic Change 109:33-57.

Sato H, Itoh A, Kohyama T, 2007. SEIB-DGVM: A new dynamic global vegetation model using a spatially explicit individual-based approach. Ecol Mod 200:279-307.

Shukla J, Nobre C, Sellers P, 1990. Amazon deforestation and climate change. Science 247:1322.

Tatem AJ, Noor AM, Von Hagen C, Di Gregorio A, Hay SI, 2007. High resolution population maps for low income nations: combining land cover and census in East Africa. PLoS One 2:e1298.

Tatem AJ, Smith DL, 2010. International population movements and regional Plasmodium falciparum malaria elimination strategies. P Natl Acad Sci 107:12222-7.

Taylor CM, Lambin EF, Stephenne N, Harding RJ, Essery RLH, 2002. The influence of land use change on climate in the Sahel. J Climate 15:3615-29.

Thomson MC, Doblas-Reyes FJ, Mason SJ, Hagedorn R, Connor SJ, Phindela T, Morse AP, Palmer TN, 2006. Malaria early warnings based on seasonal climate forecasts from multi-model ensembles. Nature 439:576-9.

Tompkins AM, Caporaso L, Biondi R, Bell JP, 2015. A generalized deforestation and land-use change scenario generator for use in climate modelling studies. PLoS One 10:e0136154.

Tompkins AM, Di Giuseppe F, 2015. Potential predictability of malaria using ECMWF monthly and seasonal climate forecasts in Africa. J Appl Meteor Clim 54:521-40.

Tompkins AM, Di Giuseppe F, Colo -González FJ, Namanya DB, 2016a. A planned operational malaria early warning system for Uganda provides useful district-scale predictions up to 4 months ahead. Climate services for health: Case studies of enhancing decision support for climate risk management and adaptation. ShumakeGuillemot J, Fernandez-Montoya L, Eds. WHO/WMO Geneva. (In press).

Tompkins AM, Ermert V, 2013. A regional-scale, high resolution dynamical malaria model that accounts for population density, climate and surface hydrology. Malaria J 12:65.

Tompkins AM, Larsen L, McCreesh N, Taylor DM, 2016b. To what extent does climate explain variations in reported malaria cases in early 20th century Uganda? Geospat Health 11:407.

Tompkins AM, McCreesh N, 2016. Migration statistics relevant for malaria transmission in Senegal derived from mobile phone data and used in an agent-based migration model. Geospat Health 11:408.

Tuno N, Okeka W, Minakawa N, Takagi M, Yan G, 2005. Survivorship of Anopheles gambiae sensu stricto (Diptera: Culicidae) larvae in western Kenya highland forest. J Med Entomol 42:270-7.

Van Vuuren DP, Stehfest E, den Elzen MJG, Kram T, van Vliet J, Deetman S, Isaac M, Klein Goldewijk K, Hof A, Mendoza Beltran A, Oostenrijk R, van Ruijven B, 2011a. RCP2.6: exploring the possibility to keep global mean temperature increase below $2 \mathrm{C}$. Climatic Change 109:95-116.

Van Vuuren DP, Edmonds J, Kainuma M, Riahi K, Thomson A, Hibbard K, Hurtt GC, Kram T, Krey V, Lamarque JF, Masui T, Meinshausen M, Nakicenovic N, ì Smith SJ, Rose SK, 2011b. The representative concentration pathways: an overview. Climatic Change 109:5-31.

Vanwambeke S0, Lambin EF, Eichhorn MP, Flasse SP, Harbach RE, Oskam L, Somboon P, van Beers S, van Benthem BHB, Walton C, RK Butlin, 2007. Impact of land-use change on dengue and malaria in northern Thailand. EcoHealth 4:37-51.

Wallace DI, Southworth BS, Shi X, Chipman JW, Githeko AK, 2014. A comparison of five malaria transmission models: benchmark tests and implications for disease control. Malaria J 13:1-16.

Walsh JF, Molyneux DH, Birley MH, 1993. Deforestation: effects on vector-borne disease. Parasitology 106:S55-75.

Wesolowski A, Eagle N, Tatem AJ, Smith DL, Noor AM, Snow RW, Buckee C0, 2012. Quantifying the impact of human mobility on malaria. Science 338:267-70.

Yasuoka J, Levins R, 2007. Impact of deforestation and agricultural development on anopheline ecology and malaria epidemiology. Am J Trop Med Hyg 76:450-60.

Zhang H, Henderson-Sellers A, McGuffie K, 1996. Impacts of tropical deforestation. part i: Process analysis of local climatic change. J Climate 9:1497-517. 